\title{
Catalytic behavior and reaction routes of MEK oxidation over Pd/ZSM-5 and Pd-Ce/ZSM-5 catalysts
}

\author{
Lin Yue, Chi He, Xinyan Zhang, Peng Li, Zhuo Wang, Hailin Wang*, Zhengping Hao** \\ Department of Environmental Nano-materials, Research Center for Eco-Environmental Sciences, Chinese Academy of Sciences, Beijing 100085, PR China
}

\section{H I G H L I G H T S}

- The MEK oxidation processes were systematically studied by thermal desorption/GC-MS technique.

- PdCe(9.6 wt\%)/ZSM-5 can offer more lattice oxygen and therefore possesses higher activity.

- Catalyst acidic changes the reaction routes and byproducts distribution.

- The oxidation products over Pd-Ce bimetallic catalysts are closely related to the surface $\mathrm{CH}_{3}{ }^{*}$ species.

\section{A R T I C L E I N F O}

\section{Article history:}

Received 9 May 2012

Received in revised form 25 October 2012

Accepted 26 October 2012

Available online 3 November 2012

\section{Keywords:}

Catalytic activity

Pd-Ce/ZSM-5 catalysts

Oxidation routes

Reaction by-products

VOCs

\section{G R A P H I C A L A B S T R A C T}

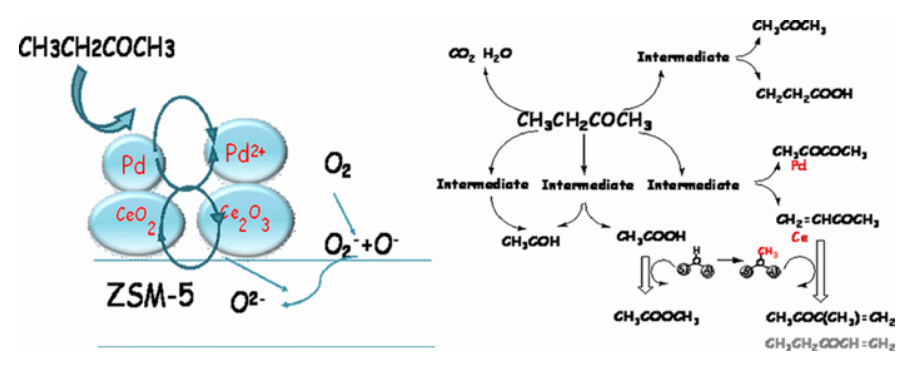

\begin{abstract}
A B S T R A C T
Catalytic oxidation is a widely used pollution control technology for removing volatile organic compounds. Pd-Ce/ZSM-5 catalysts with different Ce contents were prepared by a co-impregnation method, and their catalytic performance was investigated for the oxidation of methyl ethyl ketone (MEK). The by-products of the reaction were monitored using gas chromatography and collected in thermal desorption tubes, which were further analyzed by gas chromatography/mass spectrometry. The PdCe ${ }_{9.6} / \mathrm{ZSM}-5$ catalyst displayed the highest catalytic efficiency, as a consequence of a higher amount of strong acid sites and a superior PdO-Pd redox cycle in the presence of $\mathrm{a} \mathrm{CeO}_{2}$ additive. The introduction of $\mathrm{CeO}_{2}$ enriched the by-product species. The formation mechanisms and oxidation routes of typical by-products, such as methyl acetate, 1-penten-3-one and 3-buten-2-one, 3-methyl, during MEK oxidation over Pd-Ce/ZSM-5 catalysts was also analyzed. $\mathrm{CH}_{3}{ }^{*}$ species that formed on the catalyst were identified as reaction intermediaries. Trace amounts of acetic acid and methyl vinyl ketone were also detected and were further oxidized to methyl acetate, 1-penten-3-one and 3-buten-2-one, 3-methyl.
\end{abstract}

(c) 2012 Elsevier B.V. All rights reserved.

\section{Introduction}

The presence of volatile organic compounds (VOCs) in the atmosphere results in various environmental problems including photochemical smog, ozone depletion, and ground-level ozone generation. VOCs emitted from industrial activities can be controlled by various techniques, such as thermal incineration,

\footnotetext{
* Corresponding author. Tel.: +86 10 62843688; fax: +86 1062843688 .

** Corresponding author. Tel.: +86 10 62923564; fax: +86 1062923564 .

E-mail addresses: wanghailin@rcees.ac.cn (H. Wang), zpinghao@rcees.ac.cn (Z. Hao).
}

catalytic oxidation, adsorption, and biofiltration [1-4]. Among these, catalytic oxidation is considered to be one of the most effective and energy-saving techniques due to its potential to completely convert pollutants into carbon dioxide $\left(\mathrm{CO}_{2}\right)$ and water at low reaction temperatures.

Methyl ethyl ketone (MEK) is a commonly used solvent in several chemical industries, but emissions of MEK to the atmosphere can lead to human health concerns and wider environmental problems. Therefore, as a hazardous material, emissions of MEK into the atmosphere must be controlled. In recent years, several studies have focused on the elimination of MEK [5-11]. Some studies have identified that the partial oxidation products of MEK, such as diacetyl (DAC) and acetic acid, are generally more toxic than 
MEK [7-10]. Therefore, the reaction processes and catalytic reaction mechanisms must be clearly understood to avoid and control the formation of by-products.

Noble metals (such as Pt, Pd) [12] and metal oxides [5,13] are both catalysts for VOC oxidation. Generally, the catalytic performance of noble metal-based catalysts is higher than metal oxides. Previous studies have reported that noble metal catalysts loaded on zeolite display excellent catalytic activities in the oxidation of aromatic and chlorinated VOCs. He et al. [14] showed that the acidity of zeolites has an important role in enhancing the catalysis of VOC oxidation. Compared with Beta, MOR, and FAU zeolites, ZSM-5 displays a greater catalytic activity and is more stable [15]. Noble metal catalysts are generally accepted to be more active than metal oxide catalysts but the latter are cheaper, more thermally stable, and have a greater resistance to poisoning. Recently interest has arisen in the use of cerium (Ce) and several studies using Ce oxide $\left(\mathrm{CeO}_{2}\right)$ as an additive on a palladium (Pd)-supported catalyst have been reported [12,15-19].

The use of bimetallic metal/ZSM-5 catalysts in the MEK oxidation process has seldom been reported. In particular, the effect of $\mathrm{CeO}_{2}$ on the reaction selectivity and pathways should be further explored. The purpose of this study was to explore the oxidation route and mechanisms of MEK conversion over the Pd-Ce/ZSM-5 (PCZ) catalysts, including the formation of various by-products and their concentrations during MEK oxidation.

The following abbreviations are used throughout the text, and are summarized as follows: methyl ethyl ketone, MEK; diacetyl, DAC; methyl vinyl ketone, MVK; acetaldehyde, ACH; methyl acetate, MA; acetone, DK; acetic acid, AcOH; Pd/ZSM-5, PZ; Ce/ZSM5, CZ; Pd-Ce/ZSM-5, PCZ.

\section{Materials and methods}

\subsection{Material preparation}

ZSM-5 zeolite ( $\mathrm{Si} / \mathrm{Al}=25$; Tianjin Chemical Plant, Tianjin, China) was impregnated into aqueous solutions of $\mathrm{Ce}\left(\mathrm{NO}_{3}\right)_{2}$ (9.6 wt\%) and $\mathrm{Pd}\left(\mathrm{NO}_{3}\right)_{2}(0.5 \mathrm{wt} \%)$ to obtain the $\mathrm{CZ}$ and $\mathrm{PZ}$ catalysts, respectively. The Pd-Ce bimetallic catalysts were prepared by a similar co-impregnation method in solutions of $\mathrm{Pd}\left(\mathrm{NO}_{3}\right)_{2}(0.5 \mathrm{wt} \%)$ and $\mathrm{Ce}\left(\mathrm{NO}_{3}\right)_{2}$ (1.6wt\%, 3.2 wt\%, 6.4 wt\%, 9.6wt\%). All samples were dried at $80^{\circ} \mathrm{C}$ for $24 \mathrm{~h}$, and calcined at $500^{\circ} \mathrm{C}$ for $4 \mathrm{~h}$. The resulting catalysts were referred to as $\mathrm{CZ}, \mathrm{PZ}, \mathrm{PC}_{1.6} \mathrm{Z}, \mathrm{PC}_{3.2} \mathrm{Z}, \mathrm{PC}_{6.4} \mathrm{Z}$, and $\mathrm{PC}_{9.6} \mathrm{Z}$, respectively.

\subsection{Catalyst characterization}

X-ray diffraction (XRD) patterns were recorded on a powder diffraction system (X'Pert PRO; PANalytical, Almelo, The Netherlands) using $\mathrm{Cu} K \alpha$ radiation $(\lambda=0.15418 \mathrm{~nm})$ in the $2 \theta$ range of $10-80^{\circ}$ (scanning rate of $4 \% \mathrm{~min}$ ). $\mathrm{N}_{2}$ adsorption/desorption isotherms of the catalysts were collected at $77 \mathrm{~K}$ on a gas sorption analyzer NOVA 1200 (Quantachrome Corp., Boynton Beach, FL, USA). All samples were degassed under vacuum at $300^{\circ} \mathrm{C}$ for $3 \mathrm{~h}$ before measurement. The total pore volume was estimated from the amount of nitrogen adsorbed at a relative pressure $\left(P / P_{0}\right)$ of about 0.99 . The specific surface area $\left(S_{\mathrm{BET}}\right)$ was calculated using the Brunauer-Emmett-Teller (BET) method. The elemental composition of each sample was analyzed by X-ray fluorescence (XRF) (XRF-1800 spectrometer; Shimadzu, Kyoto, Japan) using an Rh tube as excitation source.

X-ray photoelectron spectroscopy (XPS) (AXIS-Ultra instrument; Kratos Analytical, Hadano, Japan) was undertaken using monochromatic $\mathrm{Al} \mathrm{K \alpha}$ radiation. To compensate for surface charge effects, binding energies were calibrated using the $\mathrm{C} 1 \mathrm{~s}$ hydrocarbon peak at $284.80 \mathrm{eV}$. The curve fitting was performed with CasaXPS software.

The temperature programmed reduction of $\mathrm{H}_{2}\left(\mathrm{H}_{2}-\mathrm{TPR}\right)$ was performed on a chemisorb analyzer (ChemiSorb 2720; Micrometrics, Norcross, GA, USA). TPR profiles were obtained by passing a $5 \% \mathrm{H}_{2} / \mathrm{He}$ flow $(50 \mathrm{~mL} / \mathrm{min})$ through the catalysts (approximately $50 \mathrm{mg}$ ), which had been previously dried in a helium flow $\left(50 \mathrm{~mL} / \mathrm{min}\right.$ ) at $300^{\circ} \mathrm{C}$ for $1 \mathrm{~h}$.

The temperature programmed desorption of $\mathrm{NH}_{3}\left(\mathrm{NH}_{3}-\mathrm{TPD}\right)$ was also performed on the Chemisorb 2720 analyzer. Prior to each TPD test, the sample $(50 \mathrm{mg}$ ) was pretreated in a helium flow $(50 \mathrm{~mL} / \mathrm{min})$ at $300^{\circ} \mathrm{C}$ for $1 \mathrm{~h}$. Then the samples were adsorbed with $\mathrm{NH}_{3} / \mathrm{He}(2 \% / 98 \%, \mathrm{v} / \mathrm{v})$ to saturate with $\mathrm{NH}_{3}$. The catalyst was flushed with $\mathrm{He}(50 \mathrm{~mL} / \mathrm{min})$ at room temperature to remove the physisorbed $\mathrm{NH}_{3}$. The desorption profile of $\mathrm{NH}_{3}-\mathrm{TPD}$ was then recorded from $25^{\circ} \mathrm{C}$ to $800^{\circ} \mathrm{C}$ at a heating rate of $10^{\circ} \mathrm{C} / \mathrm{min}$.

\subsection{Catalytic activity evaluation}

All evaluation experiments were performed in a continuous flow fixed-bed reactor, consisting of a steel tube $(6 \mathrm{~mm}$, i.d.) at atmospheric pressure. In each test, $0.3 \mathrm{~g}$ of the catalyst (40-60 mesh) was placed into the tube reactor. A gas containing VOCs was generated by bubbling air through the VOC saturator, which was further diluted with another airstream before reaching the reaction bed. The total flow rate was kept at $300 \mathrm{~mL} / \mathrm{min}$, i.e., a gas hourly space velocity (GHSV) of $28,000 \mathrm{~h}^{-1}$ with an MEK concentration of $1000 \mathrm{ppm}$. The reaction temperature $\left(R_{\mathrm{T}}\right)$ was first raised to $130^{\circ} \mathrm{C}$ as the feed stream passed over the reactor bed and was then stabilized for $30 \mathrm{~min}$. The reaction bed temperature was increased to the following setting and maintained for $20 \mathrm{~min}$ for online detection before the next experimental procedure.

Online analysis was performed by gas chromatography (GC; model 6820; Agilent, Santa Clara, CA, USA) and GC-mass chromatography (MS; Agilent 6890) simultaneously. A gas chromatograph equipped with a flame ionization detector (FID) and a thermal conductivity detector (TCD) was employed for the quantitative analysis, and GC-MS was used for the qualitative analysis. The by-products were collected on a Tenax TA tube for $10 \mathrm{~min}$ at each temperature point and then desorbed by a thermal desorber (Unity 2 series; Markes International Ltd., Llantrisant, UK) before passing into the GC-MS device.

\section{Results and discussion}

\subsection{Catalyst characterization}

\subsection{1. $X R D$ and BET analysis}

The XRD patterns of $\mathrm{PZ}, \mathrm{CZ}, \mathrm{PC}_{1.6} \mathrm{Z}, \mathrm{PC}_{3.2} \mathrm{Z}, \mathrm{PC}_{6.4} \mathrm{Z}$, and $\mathrm{PC}_{9.6} \mathrm{Z}$ catalysts are presented in Fig. 1. All catalysts exhibited profiles ascribable to HZSM-5 [14]. Slight differences were observed for Ce-containing samples. The $\mathrm{CeO}_{2}$ fluorite structure (JCPDS file No. 43-1002) was observed in the $\mathrm{CZ}, \mathrm{PC}_{3.2} \mathrm{Z}, \mathrm{PC}_{6.4} \mathrm{Z}$, and $\mathrm{PC}_{9.6} \mathrm{Z}$ samples, and the corresponding diffraction peak became stronger and broader as the amount of $\mathrm{CeO}_{2}$ increased. No diffraction peaks ascribable to Pd metal and oxides were observed. The Pd loading had a negligible effect on the original porous structure of the support [14].

The specific surface area $\left(S_{\mathrm{BET}}\right)$ and total pore volume $\left(D_{\mathrm{V}}\right)$ of the prepared samples are summarized in Table $1 . \mathrm{PZ}$ possesses a relatively high $S_{\mathrm{BET}}\left(330.1 \mathrm{~m}^{2} / \mathrm{g}\right)$ and $D_{\mathrm{v}}\left(0.17 \mathrm{~cm}^{3} / \mathrm{g}\right)$, which was smaller than $\mathrm{PC}_{9.6} \mathrm{Z}\left(391.7 \mathrm{~m}^{2} / \mathrm{g}\right.$ and $0.24 \mathrm{~cm}^{3} / \mathrm{g}$, respectively), but slightly larger than $C Z\left(287.6 \mathrm{~m}^{2} / \mathrm{g}\right.$ and $0.16 \mathrm{~cm}^{3} / \mathrm{g}$, respectively). In the Ce-containing samples, both the $S_{\mathrm{BET}}$ and $D_{\mathrm{v}}$ increased as the amount of $\mathrm{CeO}_{2}$ additive increased. 


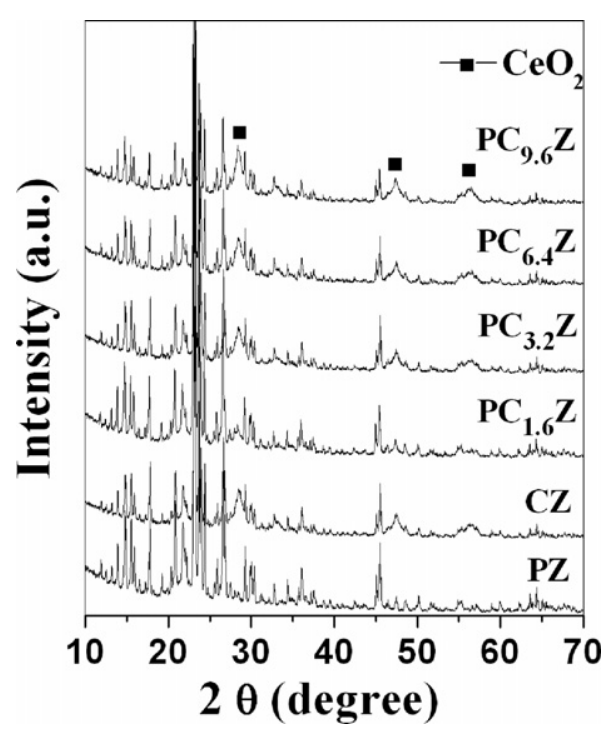

Fig. 1. XRD profiles of catalysts: $P Z, C Z, P C_{1.6} Z, P C_{3.2} Z, P C_{6.4} Z, P C_{9.6} Z$.

Table 1

Physicochemical properties of the synthesized catalysts.

\begin{tabular}{lll}
\hline Catalyst & $S_{\mathrm{BET}^{\mathrm{a}}}\left(\mathrm{m}^{2} / \mathrm{g}\right)$ & $D_{\mathrm{v}}^{\mathrm{b}}\left(\mathrm{cm}^{3} / \mathrm{g}\right)$ \\
\hline $\mathrm{PZ}$ & 330.1 & 0.17 \\
$\mathrm{CZ}$ & 287.6 & 0.16 \\
$\mathrm{PC}_{1.6} \mathrm{Z}$ & 293.1 & 0.13 \\
$\mathrm{PC}_{3.2} \mathrm{Z}$ & 309.0 & 0.18 \\
$\mathrm{PC}_{6.4} \mathrm{Z}$ & 326.4 & 0.19 \\
$\mathrm{PC}_{9.6} \mathrm{Z}$ & 391.7 & 0.24 \\
\hline
\end{tabular}

a BET specific surface area.

b Total pore volume estimated at $P / P_{0}=0.99$.

\subsection{2. $\mathrm{NH}_{3}$ temperature-programmed desorption}

$\mathrm{A} \mathrm{NH}_{3}$ temperature-programmed desorption was used to evaluate the acid strength and acid site number. The results are displayed in Fig. 2. The temperature was above $100^{\circ} \mathrm{C}$, eliminating the physisorption of $\mathrm{NH}_{3}$ [20]. For pure $\mathrm{CeO}_{2}$, only one weak desorption peak was observed at about $150^{\circ} \mathrm{C}$ [21], indicating that few weak acid sites were present. Three types of $\mathrm{NH}_{3}$ desorption peaks were observed for all catalysts investigated, corresponding to three types of acid sites. The desorption temperature and
Table 2

Acidity of $\mathrm{PZ}, \mathrm{CZ}, \mathrm{PC}_{3.2} \mathrm{Z}$ and $\mathrm{PC}_{9.6} \mathrm{Z}$ catalysts.

\begin{tabular}{|c|c|c|c|c|c|c|c|}
\hline \multirow[t]{2}{*}{ Catalyst } & \multicolumn{3}{|c|}{$\begin{array}{l}\text { Desorption temperature } \\
\left({ }^{\circ} \mathrm{C}\right)\end{array}$} & \multicolumn{4}{|c|}{ Acidity $^{\mathrm{a}}$ (mmol NH $\mathrm{m}_{3}$ g-cat) } \\
\hline & I & II & III & I & II & III & $\mathrm{I}+\mathrm{II}+\mathrm{III}$ \\
\hline $\mathrm{PZ}$ & 113 & 193 & 428 & 0.26 & 0.21 & 1.06 & 1.53 \\
\hline$C Z$ & 125 & 196 & 415 & 0.21 & 0.29 & 0.65 & 1.15 \\
\hline $\mathrm{PC}_{3.2} \mathrm{Z}$ & 111 & 194 & 381 & 0.26 & 0.29 & 1.08 & 1.63 \\
\hline $\mathrm{PC}_{9.6} \mathrm{Z}$ & 105 & 175 & 362 & 0.26 & 0.30 & 1.15 & 1.71 \\
\hline
\end{tabular}

a Amounts of $\mathrm{NH}_{3}$ desorbed at different temperatures.

quantitative molar number of acid sites are listed in Table 2. The peaks in the range of $100-200^{\circ} \mathrm{C}$ correspond to the weak acid sites [21]. The high desorption temperature peak (HT peak) in the range of $300-500{ }^{\circ} \mathrm{C}$ was attributable to ammonia desorption from the strong acid sites, which plays an important role in the catalytic reaction. From Table 2, the acidity of samples reduced as follows: $\mathrm{PC}_{9.6} \mathrm{Z}$ (1.15 mmol NH $\mathrm{m}_{3} /$ g-cat $)>\mathrm{PC}_{3.2} \mathrm{Z}\left(1.08 \mathrm{mmol} \mathrm{NH}_{3} /\right.$ g-cat $)>\mathrm{PZ}$ (1.05 mmol NH$/$ g-cat $)>\mathrm{CZ}\left(0.65 \mathrm{mmol} \mathrm{NH}_{3} /\right.$ g-cat $)$. In addition, a sharp peak at $411^{\circ} \mathrm{C}$ was observed over the $\mathrm{PC}_{3.2} \mathrm{Z}$ catalyst. This peak was present at $400^{\circ} \mathrm{C}$ for $\mathrm{PC}_{9.6} \mathrm{Z}$, which was attributable to a new interface structure between $\mathrm{Pd}$ species and $\mathrm{CeO}_{2}$ [22]. No peak was observed for the PZ and CZ catalysts.

\subsection{Hydrogen temperature-programmed reduction}

$\mathrm{H}_{2}$-TPR profiles for the $\mathrm{PZ}, \mathrm{CZ}, \mathrm{PC}_{1.6} \mathrm{Z}, \mathrm{PC}_{3.2} \mathrm{Z}, \mathrm{PC}_{6.4} \mathrm{Z}$, and $\mathrm{PC}_{9.6} \mathrm{Z}$ catalysts are displayed in Fig. 3. A negative peak at $60^{\circ} \mathrm{C}$ was observed for the $\mathrm{PZ}$ and $\mathrm{PC}_{1.6} \mathrm{Z}$ catalysts owing to the desorption of weakly adsorbed hydrogen and the decomposition of $\mathrm{PdH}_{x}$ [23]. Padmasri et al. [24] found that $\mathrm{PdCl}_{2}$ or PdO could be easily reduced to metallic Pd in a hydrogen atmosphere at ambient temperature, allowing the formation of $\mathrm{PdH}_{x}$. A peak located at about $80^{\circ} \mathrm{C}$ for the $\mathrm{PC}_{6.4} \mathrm{Z}$ and $\mathrm{PC}_{9.6} \mathrm{Z}$ catalysts was ascribed to the formation of $\mathrm{PdO}$ or $\mathrm{PdO}_{X}$. The amount of $\mathrm{PdO}$ formed increased with an increase in $\mathrm{CeO}_{2}$ content. This implies that more $\mathrm{PdO}$ was deposited on the $\mathrm{CeO}_{2}$ than on the ZSM-5. The TPR signal of $\mathrm{PC}_{9.6} \mathrm{Z}$ located at $80^{\circ} \mathrm{C}$ was weaker than that of $\mathrm{PC}_{6.4} \mathrm{Z}$, indicating that the amount of $\mathrm{CeO}_{2}$ loaded was beneficial for reduction. The peaks in the range of $350-450{ }^{\circ} \mathrm{C}$ were ascribed to the reduction of surface oxygen species, while the peaks above $600{ }^{\circ} \mathrm{C}$ were considered to represent the reduction of bulk Ce [20]. The two peaks shifted to a lower temperature and become

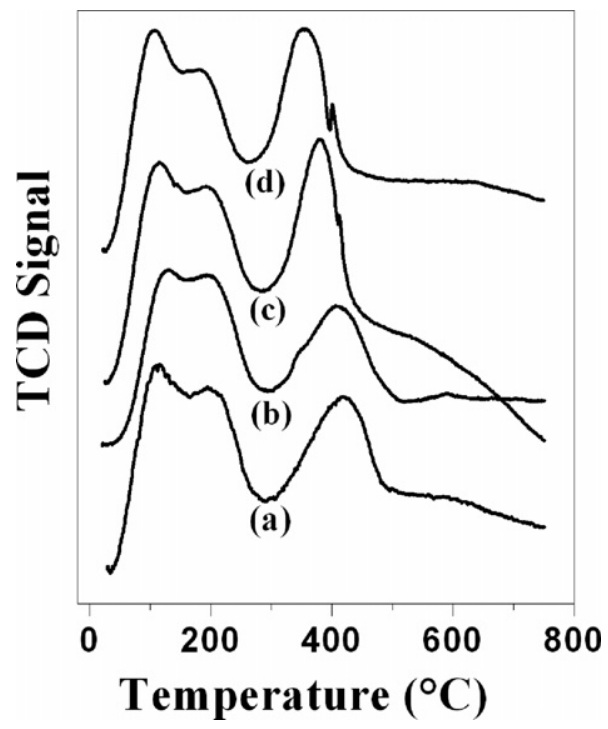

Fig. 2. $\mathrm{NH}_{3}$-TPD profiles of (a) $\mathrm{PZ}$, (b) $\mathrm{CZ}$, (c) $\mathrm{PC}_{3.2} \mathrm{Z}$ and (d) $\mathrm{PC}_{9.6} \mathrm{Z}$.

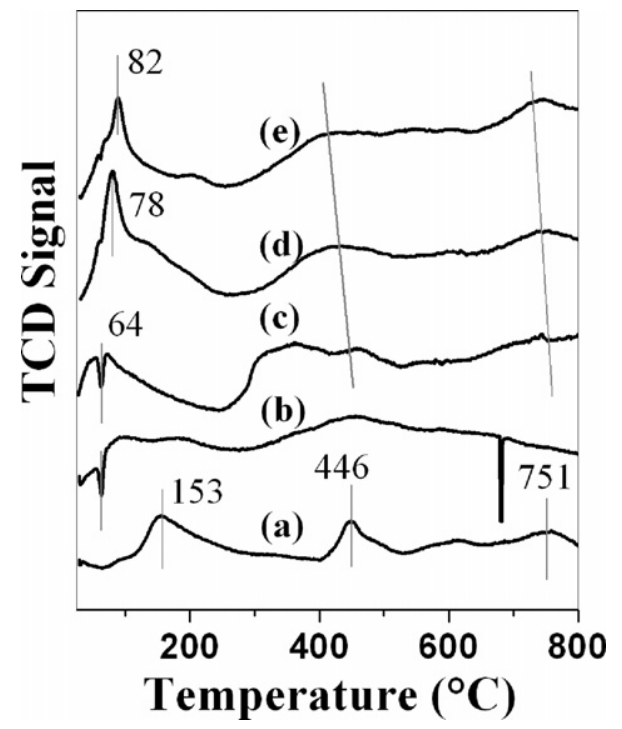

Fig. 3. $\mathrm{H}_{2}$-TPR profiles of (a) CZ, (b) $\mathrm{PZ}$, (c) $\mathrm{PC}_{1.6} \mathrm{Z}$, (d) $\mathrm{PC}_{3.2} \mathrm{Z}$ and (e) $\mathrm{PC}_{9.6} \mathrm{Z}$. 
narrower with increasing $\mathrm{CeO}_{2}$ content, which was ascribed to an interaction between $\mathrm{PdO}$ and $\mathrm{CeO}_{2}$. Luo et al. [25,26] reported that surface hydrogen atoms on $\mathrm{Pt}, \mathrm{Pd}, \mathrm{Cu}$, and $\mathrm{Ni}$ can enhance the rate of reduction of $\mathrm{CuO}, \mathrm{NiO}$, and $\mathrm{Co}_{3} \mathrm{O}_{4}$, while $\mathrm{CeO}_{2}$ can promote the rapid reoxidation of the reduced $\mathrm{Pd}$ on a $\mathrm{PCZ}$ catalyst. $\mathrm{CeO}_{2}$ is assumed to effectively reduce the reversion between $\mathrm{PdO}$ decomposition and Pd oxidation, resulting in better mobility and availability of lattice oxygen, which is enhanced by the incorporation of Ce and the strong synergistic interaction between $\mathrm{Pd}$ and $\mathrm{CeO}_{2}$.

\subsection{XPS measurement}

An XPS technique was used to determine the surface element composition and chemical states of various catalysts such as $\mathrm{PZ}$, $\mathrm{CZ}$, and $\mathrm{PC}_{9.6} \mathrm{Z}$. The high-resolution XPS spectra of Ce3d, Pd3d, and O1s core levels are shown in Fig. 4, and the surface compositions are detailed in Table 3. For the PCZ catalysts, the percentage of atomic Pd increases from $0.13 \%$ to $0.31 \%$, while the percentage of atomic oxygen decreases, indicating the formation of more oxygen vacancies on the surface of PCZ catalysts [27].

The Pd3d XPS spectra of the PZ and $\mathrm{PC}_{9.6} \mathrm{Z}$ catalysts are presented in Fig. 4b. The XPS curves could be fitted with two doublets, which were assigned to $P d 3 d_{5 / 2}$ and $P d 3 d_{3 / 2}$. The XPS results imply that $\mathrm{PdO}$ is the main species formed in the Pd-containing catalysts. In addition, highly ionic $\mathrm{Pd}^{2+}\left(\mathrm{Pd}_{3} \mathrm{~d}_{5 / 2,3 / 2}=337.8,343.1 \mathrm{eV}\right)$ existed in the catalysts due to residual $\mathrm{Pd}\left(\mathrm{NO}_{3}\right)_{2}$ from the synthesis process [28]. A similar result was reported previously [29], indicating that well-dispersed and ion deficient coordinated PdO was in intimate contact with the $\mathrm{CeO}_{2}$ support, and subsequently promoted oxygen transfer from $\mathrm{CeO}_{2}$ to $\mathrm{Pd}$ active sites.

The XPS spectra of $01 \mathrm{~s}$ core electron levels for the PZ, CZ, and $\mathrm{PC}_{9.6} \mathrm{Z}$ catalysts are shown in Fig. 4c. The corresponding binding energies (BEs) of 01s core levels and the quantitative values are summarized in Table 3. The 01s spectra can be arranged into two main regions: the lattice oxygen at the low $\mathrm{BE}$ component $\mathrm{O}_{\mathrm{I}}\left(\mathrm{O}^{2-}\right)$, and the high $\mathrm{BE}$ component $\mathrm{O}_{\|}$assigned to other surface oxygen species (chemisorbed oxygen $\mathrm{O}_{2}{ }^{-}$and $\mathrm{O}^{-}$) [30]. The $\mathrm{PZ}$ catalyst contained only the $\mathrm{O}_{\|}$-type oxygen. A higher percentage of $\mathrm{O}_{\|}$was present in $\mathrm{PC}_{9.6} \mathrm{Z}$ than $\mathrm{CZ}$. $\mathrm{O}_{\|}$species have a strong oxidizing capability and high mobility, which can enhance oxygen transfer and the redox cycle by transforming the lattice oxygen with abundant oxygen vacancies. In addition, oxygen vacancies can reportedly act as active sites for oxygen adsorption or activation [29]. This suggests that the $\mathrm{PC}_{9.6} \mathrm{Z}$ catalyst possesses more oxygen vacancies, which promotes catalytic activity.

The Ce3d core-level spectra shown in Fig. 4a indicate the presence of both $\mathrm{Ce}^{3+}$ and $\mathrm{Ce}^{4+}$. The curves are fitted into eight peaks corresponding to the two spin-orbit components ( $\mathrm{U}$ and $\mathrm{V}$ ) to distinguish $\mathrm{Ce}^{3+}$ and $\mathrm{Ce}^{4+}[29]$. The six features (u, u' $\mathrm{u}^{\prime \prime}, \mathrm{u}^{\prime \prime \prime}, \mathrm{v}, \mathrm{v}^{\prime \prime}$, and $\left.v^{\prime \prime \prime}\right)$ refer to the spectrum of $\mathrm{Ce}^{4+}$, while the other two features $\left(\mathrm{u}^{\prime}\right.$ and $\mathrm{v}^{\prime}$ ) refer to the spectra of $\mathrm{Ce}^{3+}$. A estimation of the relative amounts of $\mathrm{Ce}^{4+}$ and $\mathrm{Ce}^{3+}$ was made based on the fitted peak areas of the respective XPS Ce3d peaks, and the results are presented in Table 3. A higher amount of $\mathrm{Ce}^{4+}$ was present in $\mathrm{PC}_{9.6} \mathrm{Z}$ than that in $C Z$. These results suggest that more $O_{\|}$is present on the surface of the $\mathrm{PC}_{9.6} \mathrm{Z}$ catalyst, indicating a stronger oxidizing ability [29]. Therefore, the $O_{\|}$species on the surface was speculated to accelerate the transformation of some $\mathrm{Ce}^{3+}$ to $\mathrm{Ce}^{4+}$.

\subsection{MEK oxidation}

\subsubsection{Catalytic behavior}

The catalytic behavior of the $\mathrm{PZ}, \mathrm{CZ}, \mathrm{PC}_{1.6} \mathrm{Z}, \mathrm{PC}_{3.2} \mathrm{Z}, \mathrm{PC}_{6.4} \mathrm{Z}$, and $\mathrm{PC}_{9.6} \mathrm{Z}$ catalysts during MEK oxidation is presented in Fig. 5. Based on the $T_{90}$ values, the order of activity of the catalysts is as follows: $\mathrm{PC}_{9.6} \mathrm{Z}>\mathrm{PC}_{6.4} \mathrm{Z}>\mathrm{PC}_{3.2} \mathrm{Z}>\mathrm{PZ}>\mathrm{PC}_{1.6} \mathrm{Z}>\mathrm{CZ}$. The $\mathrm{PC}_{9.6} \mathrm{Z}$ catalyst
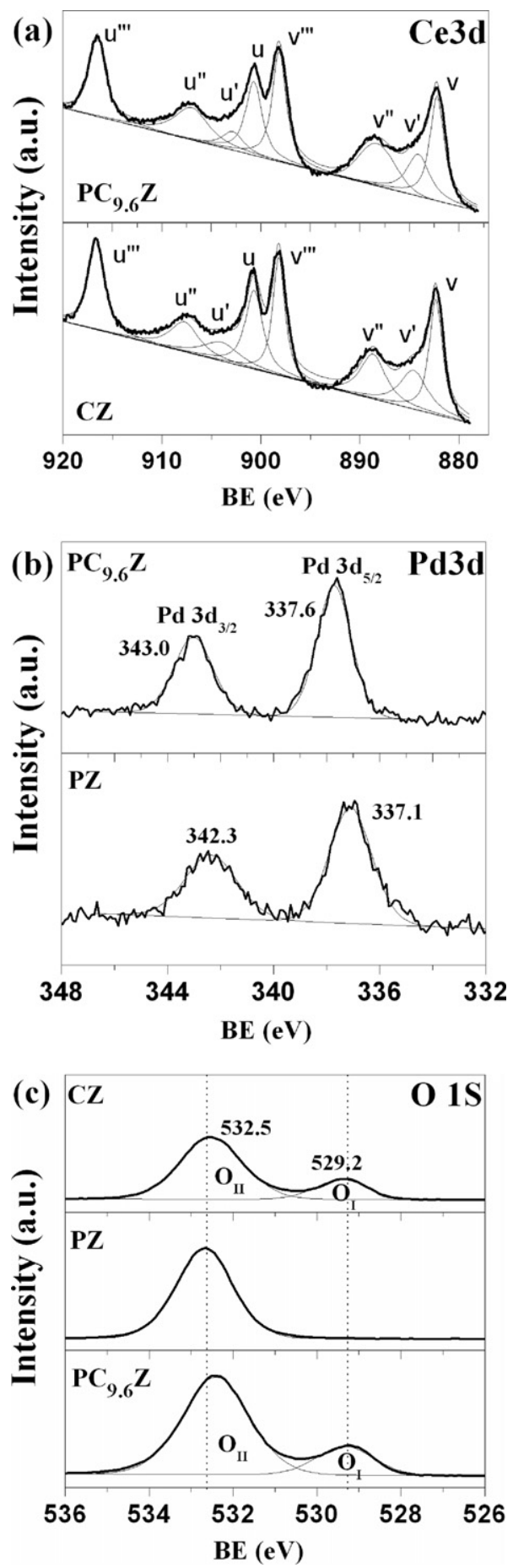

Fig. 4. XPS results of $P Z, C Z, P C_{9.6} Z$ catalysts: (a) Ce3d, (b) $P d 3 d$ and (c) 01 s.

exhibits the best catalytic performance among these samples, but $\mathrm{PC}_{1.6} \mathrm{Z}$ exhibits a lower catalytic activity compared with other $\mathrm{PCZ}$ catalysts due to the weaker interactions revealed by the $\mathrm{H}_{2}$-TPR results. Catalytic activity is strongly dependent on the nature of the support material. The PCZ catalysts were more active than the PZ catalyst. Several reasons for this are elaborated below. One of the main factors is likely to be the acidity. Pd loaded on an acidic support is reportedly more effective in catalyzing an oxidization reaction than when it is loaded on neutral or basic supports because the electrophilic character of acidic supports results in an electron deficiency in Pd atoms [31,32]. In addition, it was also determined that the PCZ catalyst with more acid sites (especially the strong acid 
Table 3

Chemical and surface compositions of various catalysts.

\begin{tabular}{|c|c|c|c|c|c|c|c|c|}
\hline \multirow[t]{2}{*}{ Catalyst } & \multirow[t]{2}{*}{$\mathrm{Pd}^{\mathrm{a}}(\mathrm{wt} \%)$} & \multicolumn{3}{|c|}{ Surface atoms percentage ${ }^{\mathrm{b}}(\%)$} & \multicolumn{2}{|c|}{$\begin{array}{l}\text { Relative abundance } \\
\text { of } \mathrm{Ce}^{3+} \text { and } \mathrm{Ce}^{4+} \mathrm{b}(\%)\end{array}$} & \multicolumn{2}{|c|}{$\begin{array}{l}\text { Relative abundance } \\
\text { of } \mathrm{O}_{\mathrm{I}} \text { and } \mathrm{O}_{\mathrm{II}} \mathrm{b}(\%)\end{array}$} \\
\hline & & $\mathrm{Pd}$ & $\mathrm{Ce}$ & $\mathrm{O}$ & $\mathrm{Ce}^{3+}$ & $\mathrm{Ce}^{4+}$ & $\mathrm{O}_{\mathrm{I}}$ & $\mathrm{O}_{\mathrm{II}}$ \\
\hline $\mathrm{PZ}$ & 0.31 & 0.13 & - & 59.36 & - & - & - & 100 \\
\hline $\mathrm{CZ}$ & - & - & 6.63 & 53.97 & 18.53 & 81.47 & 16.37 & 83.63 \\
\hline $\mathrm{PC}_{9.6} \mathrm{Z}$ & 0.47 & 0.31 & 6.65 & 54.91 & 14.91 & 85.09 & 15.16 & 84.84 \\
\hline
\end{tabular}

a Pd content by XRF analysis.

b Surface compositions by XPS analysis.

sites) has a higher catalytic activity. The redox property of Ce can be considered as another important factor. $\mathrm{CeO}_{2}$ has a cubic fluorite structure and a relatively high density of oxygen vacancies exists in the $\mathrm{CeO}_{2}$ lattice. This is in a good agreement with the $\mathrm{H}_{2}$-TPR and XPS results. During the active phase of VOC oxidation over a Pdsupported catalyst, $\mathrm{Pd}^{2+}$ has been proposed to catalyze the hydrocarbon oxidation, and $\mathrm{Pd}^{0}$ to promote the catalytic activity by maintaining a $\mathrm{Pd}^{2+}-\mathrm{Pd}^{0}$ cycle during dissociation of VOCs, thus accelerating the reaction rate [33-35]. In addition, the catalytic oxidation of VOCs usually involves the participation of surface lattice oxygen species via the Mars-van Krevelen model [36]. This effect operates when the catalyst is reduced by VOCs and is then recovered by oxidation. The available oxygen originates from either chemisorbed oxygen or lattice oxygen. Hence, the $\mathrm{Ce}^{3+} / \mathrm{Ce}^{4+}$ redox cycle can supply adequate lattice oxygen for the reaction. The detection of $\mathrm{ACH}$ as a by-product would confirm the operation of this mechanism, since $\mathrm{ACH}$, which can be observed over a long period during the catalytic oxidation, is the first oxidation intermediary of alcohols. Compared with the PZ catalyst, more ACH was formed at low temperatures on the Pd-Ce bimetallic catalysts and rapidly transformed to $\mathrm{CO}_{2}$ (the conversion temperature of $\mathrm{ACH}$ to $\mathrm{CO}_{2}$ is lower) at high temperatures. Therefore, $\mathrm{CeO}_{2}$ could provide a convenient pathway for the oxygen atoms to approach or dissociate from the Pd active species, which leads to an increase in catalytic activity.

\subsubsection{The distribution of the by-products of MEK oxidation}

For efficient VOC catalytic oxidation, not only is an understanding of the catalytic activity important, but the reaction process is also crucial and needs to be investigated [7-11]. In the present work, when PZ was used as a catalyst for MEK oxidation, the by-products were mainly $\mathrm{ACH}, \mathrm{DK}$, and DAC, as well as trace

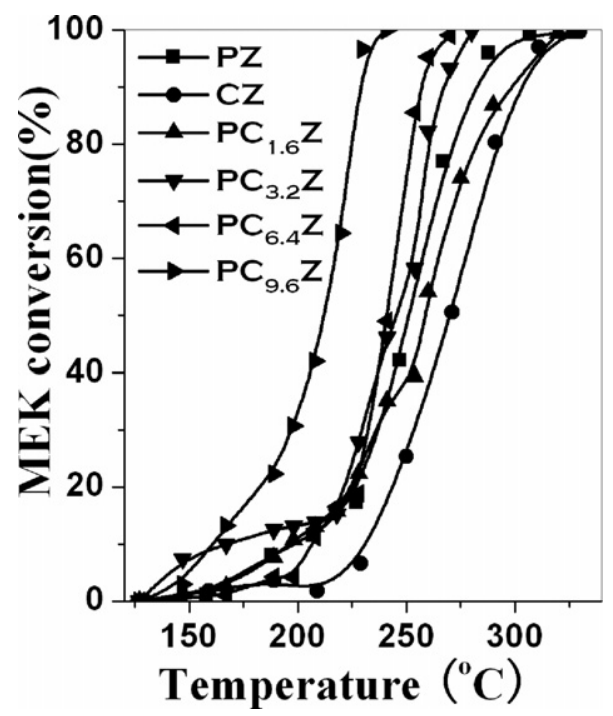

Fig. 5. Catalytic behaviors of $\mathrm{PZ}, \mathrm{CZ}, \mathrm{PC}_{1.6} \mathrm{Z}, \mathrm{PC}_{3.2} \mathrm{Z}, \mathrm{PC}_{6.4} \mathrm{Z}, \mathrm{PC}_{9.6} \mathrm{Z}$ catalysts for MEK decomposition. amounts of $\mathrm{AcOH}$ and propionic acid. However, the incorporation of $\mathrm{CeO}_{2}$ affects the acidic sites and the resulting by-products [37]. When $\mathrm{CeO}_{2}$ were incorporated into the catalyst system, MVK and MA were the main by-products, and trace amounts of 1-penten-3one and 3-buten-2-one, 3-methyl were observed. These results are completely different from previous reports [5-10], in which MA, 1-penten-3-one and 3-buten-2-one, 3-methyl have never been observed arising from the MEK oxidation process. Fig. 6 exhibits the yields (moles of MEK converted into by-product/moles of initial MEK) of the main reaction products obtained on the $P Z, C Z, P_{1.6} Z$, $\mathrm{PC}_{3.2} \mathrm{Z}, \mathrm{PC}_{6.4} \mathrm{Z}$, and $\mathrm{PC}_{9.6} \mathrm{Z}$ catalysts. By increasing the amount of $\mathrm{CeO}_{2}$ on the $\mathrm{PCZ}$ catalysts, the amount of by-products generated increased, which suggests that the presence of the Ce species is the main factor leading to the partial oxidation of MEK. Fig. 6 shows that the amount of $\mathrm{ACH}$ generated from all these catalysts was similar (below 7.0E-3) in the working range of $120-300^{\circ} \mathrm{C}$. DK and $\mathrm{DAC}$ are formed at $130^{\circ} \mathrm{C}$ and are transformed into $\mathrm{CO}_{2}$ at temperatures lower than $280^{\circ} \mathrm{C}$. In the working range of $230-260^{\circ} \mathrm{C}$, MEK is transformed to MA and MVK over catalysts containing Ce. The MS signal resulting from thermal desorption/GC-MS and the relative molar ratio attained by GC are clearly presented in Table 4. A trace amount of AcOH was detected by GC/MS. The AcOH signature disappears at $230^{\circ} \mathrm{C}$ over $\mathrm{PC}_{9.6} \mathrm{Z}$, which is higher than that over $\mathrm{PZ}$ and $\mathrm{CZ}$. Propionic acid appeared at a higher temperature $\left(260^{\circ} \mathrm{C}\right)$ over a $\mathrm{PZ}$ catalyst, whereas it formed at $167^{\circ} \mathrm{C}$ over the $\mathrm{CZ}$ and $\mathrm{PC}_{9.6} \mathrm{Z}$ catalysts. 1-Penten-3-one and 3-buten-2-one, 3-methyl collected by thermal desorption tubes produced a more intensive $\mathrm{MS}$ signal over $\mathrm{CZ}$ than that over $\mathrm{PC}_{9.6} \mathrm{Z}$. As a result of by-product formation, the $\mathrm{CO}_{2}$ yield was low over all catalysts at temperatures below $200^{\circ} \mathrm{C}$. At higher reaction temperatures, all of the by-products were transformed into $\mathrm{CO}_{2}$ and $\mathrm{H}_{2} \mathrm{O}$.

\subsubsection{MEK oxidation routes}

McCullagh et al. [8] reported that enol was involved as an intermediate during MEK oxidation over some catalysts under specific reaction conditions and particularly under a high oxygen partial pressure. The study proposed four reaction pathways of MEK oxidation. In the present work, the main reaction by-products obtained over the $\mathrm{PZ}, \mathrm{CZ}$, and $\mathrm{PC}_{9.6} \mathrm{Z}$ catalysts were recorded from online GC. Trace amounts of by-products can also be measured by gathering the reaction gases into a thermal desorption tube followed by GC/MS analysis. MEK oxidation over PCZ may proceed through different reaction mechanisms, based on the experimental results.

In particular, $\mathrm{ACH}$ is the primary $\mathrm{C}_{2}$ scission product of MEK. The diol (butane-2,3-diol) as an intermediate is oxidatively cleaved to form two ACHs. In addition, AcOH is also formed, originating from the direct scission of the enol [8]. The former is the major step among the two pathways mentioned above.

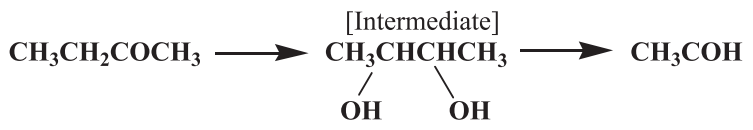

The formation of MA is related to the Ce species incorporated in the catalyst (Fig. 6). MA is hypothesized to be formed via $\mathrm{AcOH}$ 

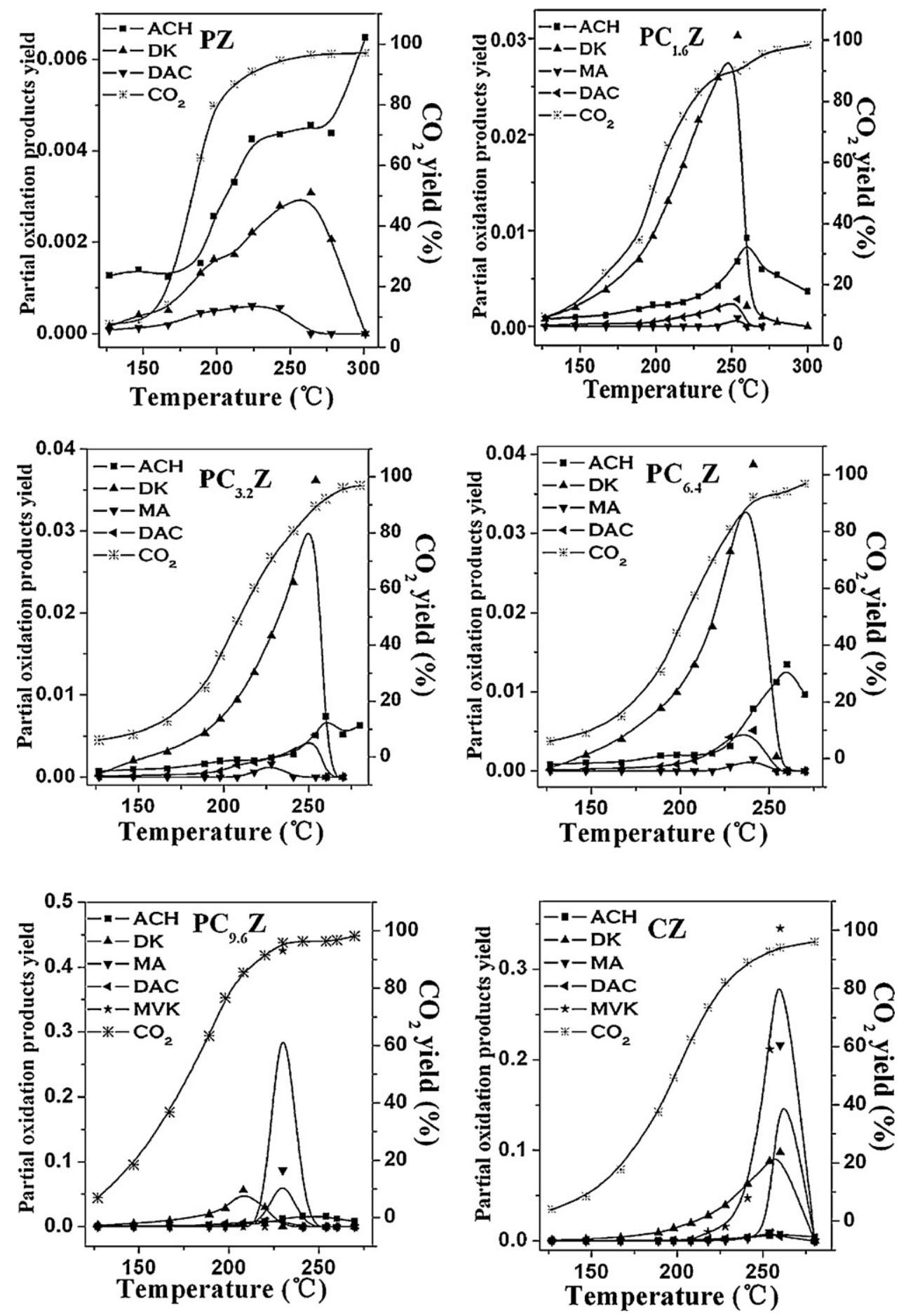

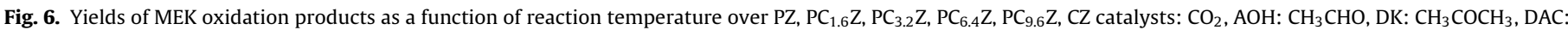
$\mathrm{CH}_{3} \mathrm{COCOCH}_{3}$, MVK: $\mathrm{CH}_{2}=\mathrm{CHCOCH}_{3}$, MA: $\mathrm{CH}_{3} \mathrm{COOCH}_{3}$.

reacting with a methyl group or formaldehyde in the temperature range of $230-250^{\circ} \mathrm{C}$. However, no direct evidence of formaldehyde formation during the reaction process exists. Compared to $\mathrm{PZ}$ and $\mathrm{CZ}$, the PCZ catalysts possess more strong acid sites. Therefore, one may logically conclude that abundant $\mathrm{CH}_{3}{ }^{*}$ species are more likely to be formed over the PCZ catalyst.
DAC and MVK appear to be formed via the same intermediate (3-hydroxybutan-2-one) by the dehydrogenation and dehydration process, respectively [7]. The selectivity for DAC formation in MEK oxidation has been observed over vanadium phosphorous catalysts, which is considered to be a consequence of attacking $n$-butane

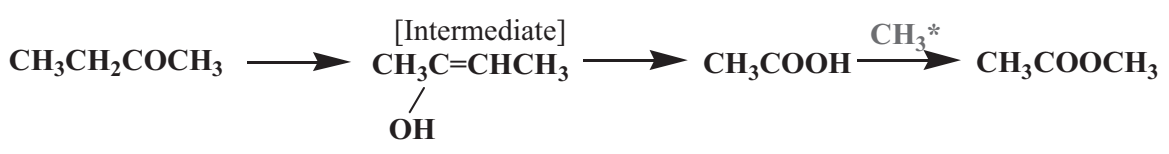




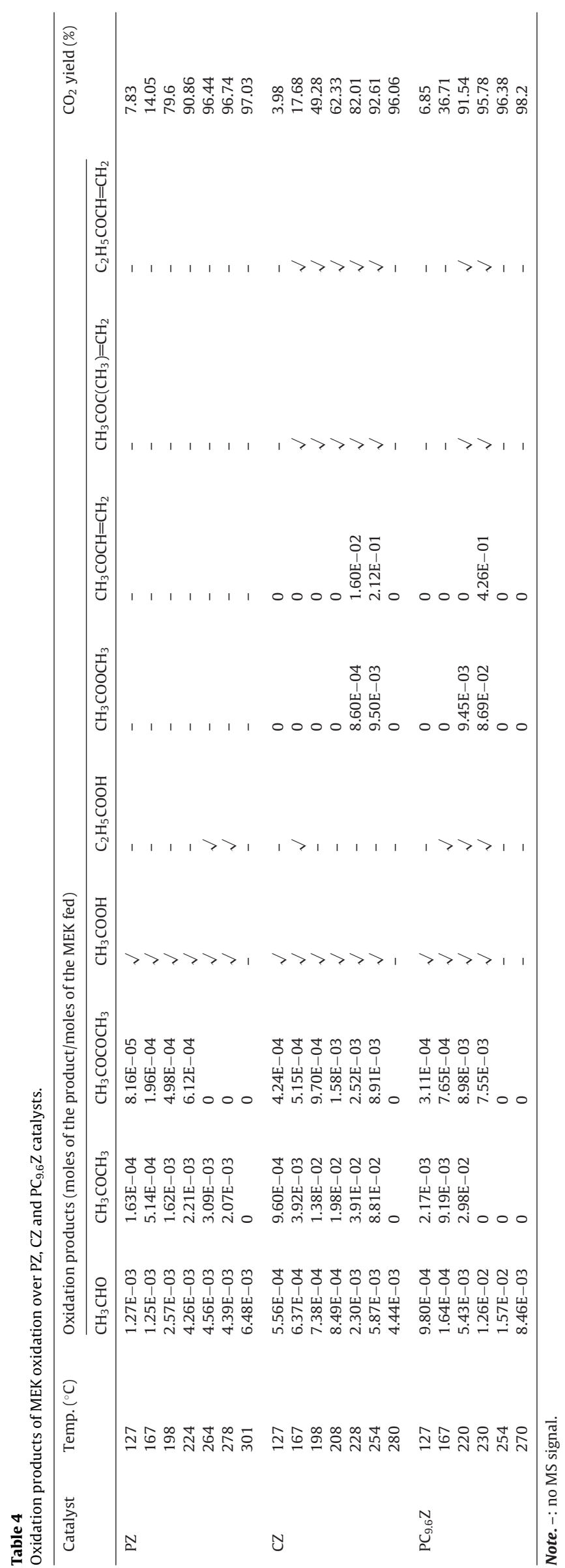

selectively at the methylene carbons [38]. In our present work, the dehydrogenation of the intermediate that occurred over the PZ catalyst is the only pathway in the parallel reactions. This result is consistent with Ai's [7] conclusion that MVK may be not an intermediate for the formation of DAC from MEK. A similar process has been previously reported for the catalytic combustion of 2-propanol over $\mathrm{Au}-\mathrm{Al}_{2} \mathrm{O}_{3}$ [39]. The study suggested that gold favored dehydrogenation as a result of dehydroxilation of surface. However, less DAC than MVK was formed over Ce-containing catalysts. The introduction of $\mathrm{CeO}_{2}$ to the $\mathrm{PZ}$ catalysts likely changed the acidic properties, which promoted the transformation of 3hydroxybutan-2-one (intermediate) into MVK by dehydration.

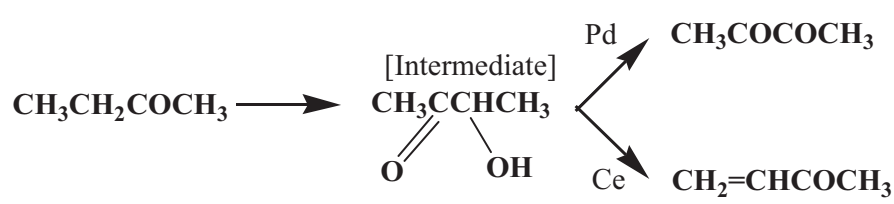

Moreover, MVK is considered to be an intermediate in the formation of 1-penten-3-one and 3-buten-2-one, 3-methyl. As mentioned previously, the surface $\mathrm{CH}_{3}{ }^{*}$ species substituted two different $\alpha-C$ positions of MVK, forming 1-penten-3-one and 3buten-2-one, 3-methyl. From the MS signal (not shown here), the abundance of the latter was twice higher than the former, which suggests a stable molecular structure.<smiles>C=CC(=O)OCCC(=C)C</smiles>

The presence of propionic acid and DK confirms that the $\mathrm{C}=\mathrm{C}$ bond scission possibly occurs not only in the $\mathrm{C}_{2}$ position, but also in $\mathrm{C}_{1}$ or $\mathrm{C}_{3}$. The scission products of $\mathrm{CH}_{2}=\mathrm{C}(\mathrm{OH}) \mathrm{CH}_{2} \mathrm{CH}_{3}$ (intermediate) are propionic acid and DK [40]. More DK appeared over the $P C Z$ and $C Z$ catalysts than over PZ, as shown in Table 4. One may reasonably conclude that the mobility of oxygen species from Ce-containing catalysts suggests the diol oxidation route is favored.

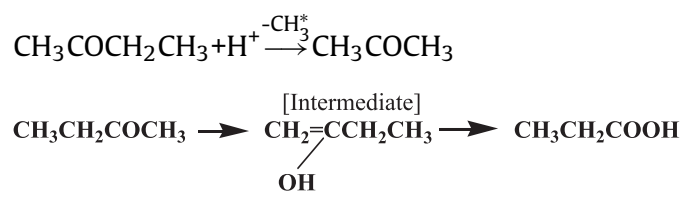

Ketones possess a weak base on the carbonyl group. The reaction has been confirmed and is closely connected to the strength of the acid on the support material [9]. Basic oxides and acidic oxides with various acid base properties have been shown to generate different reaction processes [8]. In this study, $\mathrm{CeO}_{2}$ as a neutral oxide altered the strong acidity of ZSM-5. One may hypothesize that more cracking and scission reactions take place on the stronger acid sites over the PCZ catalysts, and deeper oxidation occurs over the monometallic PZ or $\mathrm{CZ}$ catalysts. The secondary by-products that are formed (MA, 1-penten-3-one, and 3-buten-2-one, 3-methyl) are related to the stronger acid sites. Low activity leads to an abundance of byproducts through a long reaction period. Thus, the $\mathrm{CZ}$ catalyst with the lowest catalytic performance produced the maximum levels of by-products. In addition, a higher oxidation capability over the PCZ catalyst, with a higher $\mathrm{CeO}_{2}$ content, was linked to a stronger potential for scission. As a result, the $\mathrm{C}=\mathrm{C}$ bond can be easily broken, generating more complex side products. 


\section{Conclusions}

In summary, a series of ZSM-5-based Pd catalysts, with or without Ce additives, were prepared by an impregnation method. The catalytic processes of MEK oxidation over the $\mathrm{PZ}, \mathrm{CZ}, \mathrm{PC}_{1.6} \mathrm{Z}$, $\mathrm{PC}_{3.2} \mathrm{Z}, \mathrm{PC}_{6.4} \mathrm{Z}$, and $\mathrm{PC}_{9.6} \mathrm{Z}$ catalysts were studied by $\mathrm{GC}$ and thermal desorption/GC-MS techniques. The $\mathrm{PC}_{9.6} \mathrm{Z}$ catalyst was determined to possess the best catalytic activity. The addition of $\mathrm{CeO}_{2}$ significantly enhanced the strong acid sites of Pd-containing catalysts and increased the reoxidation of active phase $\mathrm{Pd}$, thus reducing the reversion process of the PdO-Pd cycle. The catalytic MEK oxidation process could be explained by the Mars-van Krevelen mechanism.

Monometallic PZ catalysts were the most selective catalysts for the complete oxidation of MEK. The oxidation products of MEK on the Pd-Ce (different Ce contents)/ZSM-5 catalysts in excess oxygen included $\mathrm{ACH}, \mathrm{AcOH}, \mathrm{DK}, \mathrm{DAC}$, propionic acid, MVK, $\mathrm{MA}, 1$-penten-3-one, 3-buten-2-one, 3-methyl, $\mathrm{CO}_{2}$, and $\mathrm{H}_{2} \mathrm{O}$. The different oxidation pathways can be attributed to the following: first, Ce-containing catalysts promoted the dehydration of intermediate (3-hydroxybutan-2-one) to form MVK and second, second-order products such as MA, 1-penten-3-one, and 3-buten2-one, 3-methyl were formed over PCZ catalysts. $\mathrm{CeO}_{2}$ is not only the promoter of the catalytic reaction, but also contributes to the formation of more strong acid sites that produce more by-products.

\section{Acknowledgements}

This work was financially supported by National High Technology Research and Development Program of China (2012AA063101), National Basic Research Program of China (2010CB732300) and the "Strategic Priority Research Program" of the Chinese Academy of Sciences (XDB05050200).

\section{References}

[1] J.J. Li, X.Y. Xu, Z. Jiang, Nanoporous silica-supported nanometric palladium: synthesis, characterization, and catalytic deep oxidation of benzene, Environ. Sci. Technol. 39 (2005) 1319-1323.

[2] H. Huang, F. Haghighat, P. Blondeau, Volatile organic compounds (VOCs) adsorption on material: influence of gas phase concentration, relative humidity and VOC type, Indoor Air 16 (2006) 236-247.

[3] L. Zou, Y.G. Luo, M. Hooper, Removal of VOCs by photocatalysis process using adsorption enhanced $\mathrm{TiO}_{2}-\mathrm{SiO}_{2}$ catalyst, Chem. Eng. Process. 45 (2006) 959-964.

[4] C. He, F.W. Zhang, L. Yue, X.S. Shang, J.S. Chen, Z.P. Hao, Nanometric palladium confined in mesoporous silica as efficient catalysts for toluene oxidation at low temperature, Appl. Catal. B: Environ. 111-112 (2012) 46-57.

[5] V.R. Choudhary, G.M. Deshmukh, Kinetics of the complete combustion of dilute propane and methyl ethyl ketone over $\mathrm{Cr}$-doped $\mathrm{ZrO}_{2}$ catalyst, Chem. Eng. Sci. 60 (2005) 1575-1581.

[6] G.P. Escobar, A.Q. Beroy, M.P.P. Iritia, H. Huerta, Kinetic study of the combustion of methyl-ethyl ketone over $\alpha$-hematite catalyst, Chem. Eng. J. 102 (2004) 107-117.

[7] M. Ai, Oxidation of methyl ethyl ketone to diacetyl on $\mathrm{V}_{2} \mathrm{O}_{5}-\mathrm{P}_{2} \mathrm{O}_{5}$ catalysts, J. Catal. 89 (1984) 413-421.

[8] E. McCullagh, J.B. McMonagle, B.K. Hodnett, Kinetic study of the selective oxidation of butan-2-one to diacetyl over vanadium phosphorus oxide, Appl. Catal. A: Gen. 93 (1993) 203-217.

[9] G. Arzamendi, V.A. Delapenaoshea, M.C. Alvarez-Galvan, J.L.G. Fierro, P.L. Arias, L.M. Gandia, Kinetics and selectivity of methyl-ethyl-ketone combustion in air over alumina-supported $\mathrm{PdO}_{X}-\mathrm{MnO}_{X}$ catalysts, J. Catal. 261 (2009) 50-59.

[10] M.C. Alvarez-Galvan, V.A. delaPenaOshea, G. Arzamendi, B. Pawelec, L.M. Gandia, J.L.G. Fierro, Methyl ethyl ketone combustion over La-transition metal $(\mathrm{Cr}$, Co, Ni, Mn) perovskites, Appl. Catal. B: Environ. 92 (2009) 445-453.

[11] J. Tsou, P. Magnoux, M. Guisnet, J.J.M. Orfao, J.L. Figueiredo, Catalytic oxidation of methyl-isobutyl-ketone over basic zeolites, Appl. Catal. B: Environ. 51 (2004) 129-133.

[12] K. Bendahou, L. Cherif, S. Siffert, H.L. Tidahy, H. Benaissa, A. Aboukais, The effect of the use of lanthanum-doped mesoporous SBA-15 on the performance of Pt/SBA-15 and Pd/SBA-15 catalysts for total oxidation of toluene, Appl. Catal. A: Gen. 351 (2008) 82-87.
[13] S.M. Saqer, D.I. Kondarides, X.E. Verykios, Catalytic oxidation of toluene over binary mixtures of copper, manganese and cerium oxides supported on $\gamma$ $\mathrm{Al}_{2} \mathrm{O}_{3}$, Appl. Catal. B: Environ. 103 (2011) 275-286.

[14] C. He, Q. Li, P. Li, Y.F. Wang, X.Y. Zhang, J. Cheng, Z.P. Hao, Templated silica with increased surface area and expanded microporosity: synthesis, characterization and catalytic application, Chem. Eng. J. 162 (2010) 901-909.

[15] C. He, J.J. Li, J. Cheng, L.D. Li, P. Li, Z.P. Hao, Z.P. Xu, Comparative studies on porous material-supported Pd catalysts for catalytic oxidation of benzene toluene and ethyl acetate, Ind. Eng. Chem. Res. 48 (2009) 6930-6936.

[16] M.E. Swanson, H.L. Greene, S. Qutubuddin, Reactive sorption of chlorinated VOCs on ZSM-5 zeolites at ambient and elevated temperatures, Appl. Catal. B: Environ. 52 (2004) 91-108.

[17] X. Zhu, L.L. Lobban, R.G. Mallinson, D.E. Resasco, Bifunctional transalkylation and hydrodeoxygenation of anisole over a Pt/HBeta catalyst, J. Catal. 281 (2011) 21-29.

[18] R. Bonelli, C. Lucarelli, T. Pasini, L.F. Liotta, S. Zacchini, S. Albonetti, Tota oxidation of volatile organic compounds on $\mathrm{Au} / \mathrm{FeO}$ catalysts supported on mesoporous SBA-15 silica, Appl. Catal. A: Gen. 400 (2011) 54-60.

[19] S. Colussi, A. Trovarelli, E. Vesselli, A. Baraldi, G. Comelli, G. Groppi, J. Llorca Structure and morphology of $\mathrm{Pd} / \mathrm{Al}_{2} \mathrm{O}_{3}$ and $\mathrm{Pd} / \mathrm{CeO}_{2} / \mathrm{Al}_{2} \mathrm{O}_{3}$ combustion catalysts in Pd-PdO transformation hysteresis, Appl. Catal. A: Gen. 390 (2010) $1-10$.

[20] J.M. Zhou, L. Zhan, Q.Q. Huang, R.X. Zhou, X.K. Li, Catalytic activity of Y zeolite supported $\mathrm{CeO}_{2}$ catalysts for deep oxidation of 1,2-dichloroethane (DCE), Catal. Lett. 127 (2009) 277-284.

[21] C. He, P. Li, J. Cheng, H.L. Wang, J.J. Li, Q. Li, Z.P. Hao, Synthesis and characterization of Pd/ZSM-5/MCM-48 biporous catalysts with superior activity for benzene oxidation, Appl. Catal. A: Gen. 382 (2010) 167-175.

[22] K. Kili, F. Le Normand, Modification of the catalytic properties of palladium by rare earth ( $\mathrm{La}, \mathrm{Ce}$ ) addition catalytic activity and selectivity in hydrocarbon conversion, J. Mol. Catal. A 140 (1999) 267-285.

[23] P. Sangeetha, K. Shanthi, K.S. Rama Rao, B. Viswanathan, P. Selvam, Hydrogenation of nitrobenzene over palladium-supported catalysts-effect of support, Appl. Catal. A: Gen. 353 (2009) 160-165.

[24] A.H. Padmasri, A. Venugopal, J. Krishnamurthy, K.S.R. Rao, P.K. Rao, Novel calcined $\mathrm{Mg}-\mathrm{Cr}$ hydrotalcite supported Pd catalysts for the hydrogenolysis of $\mathrm{CCl}_{2} \mathrm{~F}_{2}$, J. Mol. Catal. A: Chem. 181 (2002) 73-80.

[25] M.F. Luo, Z.Y. Hou, X.X. Yuan, X.M. Zheng, Characterization study of $\mathrm{CeO}_{2}$ supported Pd catalyst for low-temperature carbon monoxide oxidation, Catal. Lett. 50 (1998) 205-209.

[26] C. Shi, L. Yang, J.X. Cai, Cerium promoted Pd/HZSM-5 catalyst for methane combustion, Fuel 86 (2007) 106-112.

[27] T. Tabakova, F. Boccuzzi, M. Manzoli, J.W. Sobczak, V. Idakie, D. Andreeva, Effect of synthesis procedure on the low-temperature WGS activity of Au/ceria catalysts, Appl. Catal. B: Environ. 49 (2004) 73-81.

[28] P. Li, C. He, J. Cheng, C.Y. Ma, B.J. Dou, Z.P. Hao, Catalytic oxidation of toluene over $\mathrm{Pd} / \mathrm{CO}_{3} \mathrm{AlO}$ catalysts derived from hydrotalcite-like compounds: effects of preparation methods, Appl. Catal. B: Environ. 101 (2011) 570-579.

[29] Y.T. Chen, H.J. Zheng, Z. Guo, C.M. Zhou, C. Wang, A. Borgna, Pd catalysts supported on $\mathrm{MnCeO}_{X}$ mixed oxides and their catalytic application in solvent-free aerobic oxidation of benzyl alcohol: support composition and structure sensitivity, J. Catal. 283 (2011) 34-44.

[30] F. Arena, G. Trunfio, B. Fazio, J. Negro, L. Spadaro, Nanosize effects, physicochemical properties and catalytic oxidation pattern of the redox precipitated $\mathrm{MnCeO}_{X}$ system, J. Phys. Chem. C 113 (2009) 2822-2829.

[31] K. Okumura, T. Kobayashi, H. Tanaka, M. Niwa, Toluene combustion over palladium supported on various metal oxide supports, Appl. Catal. B: Environ. 44 (2003) 325-331.

[32] K. Muto, N. Katada, M. Niwa, Complete oxidation of methane on supported palladium catalyst: support effect, Appl. Catal. A: Gen. 134 (1996) 203-215.

[33] N.K. Nag, A study on the formation of palladium hydride in a carbon-supported palladium catalyst, J. Phys. Chem. B 105 (2001) 5945-5949.

[34] L.S. Feio, J.C. Escritori, F.B. Noronha, C.E. Hori, Combustion of butyl carbitol using supported palladium catalysts, Catal. Lett. 120 (2008) 229-235.

[35] H.L. Tidahy, S. Siffert, J.F. Lamonier, R. Cousin, E.A. Zhilinskaya, A. Aboukaïs, B.L. $\mathrm{Su}, \mathrm{X}$. Canet, G. DeWeireld, M. Frère, J.M. Giaudon, G. Leclercq, Influence of the exchanged cation in Pd/BEA and Pd/FAU zeolites for catalytic oxidation of VOCs, Appl. Catal. B: Environ. 70 (2007) 377-383.

[36] A. Aranzabal, J.A. González-Marcos, J.L. Ayastuy, J.R. González-Velasco, Kinetics of Pd/alumina catalysed 1,2-dichloroethane gas-phase oxidation, Chem. Eng. Sci. 61 (2006) 3564-3576.

[37] P.A. Weyrich, H. Treviño, W.F. Hölderich, W.M.H. Sachtler, Characterization of Ce promoted, zeolite supported Pd catalysts, Appl. Catal. A: Gen. 163 (1997) 31-44.

[38] E. Mccullagh, J.B. Mcmonagle, B.K. Hodnett, Selective oxidation of methyl ethy ketone to diacetyl over vanadium phosphorus oxide catalysts, Stud. Surf. Sci. Catal. 59 (1991) 437-444.

[39] M.A. Centeno, M. Paulis, M. Montes, J.A. Odriozola, Catalytic combustion of volatile organic compounds on $\mathrm{Au} / \mathrm{CeO}_{2} / \mathrm{Al}_{2} \mathrm{O}_{3}$ and $\mathrm{Au} / \mathrm{Al}_{2} \mathrm{O}_{3}$ catalysts, Appl. Catal. A: Gen. 234 (2002) 65-78.

[40] E. Bhan, A. Iglesia, A link between reactivity and local structure in acid catalysis on zeolites, Acc. Chem. Res. 41 (2008) 559-567. 